\title{
Race, Ethnicity, Education, Poverty, and First Cigarette Flavor
}

\author{
Shervin Assari ${ }^{1,2, *}{ }^{(\mathbb{D}}$ \\ 'Department of Urban Public Health, Charles R. Drew University of Medicine and Science, Los Angeles, CA 90059, \\ USA \\ ${ }^{2}$ Department of Family Medicine, Charles R. Drew University of Medicine and Science, Los Angeles, CA 90059, \\ USA
}

Corresponding Author: Shervin Assari, MD, MPH, Associate Professor, Department of Family Medicine, Charles R. Drew University of Medicine and Science, Los Angeles, USA. Tel: +1-734-2320445, Fax: +1-734-6158739, Email: assari@umich.edu

Received May 19, 2021; Accepted August 11, 2021; Online Published September 2, 2021

\begin{abstract}
Introduction: Research shows that race, ethnicity, and socioeconomic status (SES) have multiplicative rather than additive effects on the risk of cigarette smoking. In a national sample of American adult smokers, this study tested (1) the effects of race, ethnicity, educational attainment, and poverty status on first cigarette flavor in a national sample of American adult smokers, and (2) racial and ethnic differences in the effects of educational attainment and poverty status on first cigarette flavor.

Methods: This cross-sectional study entered 22,144 ever-smoker adults who had participated in the Population Assessment of Tobacco and Health (PATH; 2013), a nationally representative study in the US. Independent variables were race, ethnicity, educational attainment, and poverty status. There were three dependent variables: initiating smoking using any, menthol/mint, and candy/fruit-flavored cigarettes. Age, sex, and region were the covariates.

Results: Black individuals had higher odds of initiating smoking using menthol/mint-flavored cigarettes $(\mathrm{OR}=3.86,95 \% \mathrm{Cl}=3.55-4.20)$, and Hispanics had higher odds of initiating smoking using candy/fruit-flavored cigarettes $(\mathrm{OR}=1.79,95 \% \mathrm{Cl}=1.44-2.21)$. Overall, individuals with higher education had lower odds of initiating smoking using menthol/mint-flavored cigarettes $(\mathrm{OR}=0.94,95 \% \mathrm{Cl}=0.92$ 0.96), but higher odds of candy/fruit-flavored cigarettes $(\mathrm{OR}=1.35,95 \% \mathrm{Cl}=1.26-1.45)$. Living out of poverty was not associated with initiating smoking using flavored cigarettes.

Conclusion: In the US, race, ethnicity, and SES show multiplicative rather than additive effects on first cigarette flavor.

Keywords: Population Groups, Socioeconomic Status, Tobacco Use, Smoking
\end{abstract}

Citation: Assari S. Race, ethnicity, education, poverty, and first cigarette flavor. Int J Travel Med Glob Health. 2021;9(3):132-138. doi:10.34172/ ijtmgh.2021.22.

\section{Introduction}

Tobacco use is one of the main causes of morbidity and mortality both globally and in the US. ${ }^{1,2}$ Not only is tobacco use associated with a wide range of cancers $^{3,4,5}$ it can also deterioriate oral health. ${ }^{6,7}$ As such, prevention of tobacco use may be an important strategy to improve population health. ${ }^{8}$

Despite a considerable decline, tobacco use remains the leading preventable cause of morbidity and mortality in the US, especially for populations with a low socioeconomic status (SES). ${ }^{9-11}$ Each year, tobacco takes 480,000 lives in the US and causes 16 million tobacco-related chronic diseases. ${ }^{12}$ Additionally, in the US, tobacco imposes 300 billion dollars each year for combined direct and indirect costs. ${ }^{13}$
Although the US has successfully reduced the overall rate of tobacco use, ${ }^{9-11}$ the same success is not achieved in reducing social inequality in tobacco use. ${ }^{9-11}$ More than ever before, tobacco use is unequally impacting social groups of Americans; the prevalence and burden of tobacco use do not follow a pattern of random distribution in the US. ${ }^{14-18}$ As a result of a massive success in reducing tobacco-related morbidity and mortality in high SES populations, tobacco use has shifted from a mainstream public health challenge to one that mainly affects marginalized populations based on their SES, race, and ethnicity. ${ }^{19}$ Such wideing of social inequalities in the US poses a major threat to the country's progress towards tobacco control. ${ }^{19}$

Copyright $\odot 2021$ The Author(s). This is an open-access article distributed under the terms of the Creative Commons Attribution License (http:// creativecommons.org/licenses/by/4.0), which permits unrestricted use, distribution, and reproduction in any medium, provided the original work is properly cited. 
Racial and ethnic minorities ${ }^{14-18}$ and low SES groups ${ }^{20-22}$ have remained at an increased risk of tobacco burden in the US. $^{22-24}$ Black and Latino advantages have narrowed, while SES disparities in tobacco use have widened. ${ }^{22-24}$ From 1966 to 2015 , cigarette smoking declined by $83 \%$ and $40 \%$ in American adults with a college degree and those who did not graduate from high school, respectively. ${ }^{19}$ More recent research has shown that some racial, ethnic, and SES disparities in tobacco use are due to predatory tobacco marketing in low SES Black and Hispanic neighborhoods. ${ }^{25-27}$ As a result of predatory marketing, low SES, Black, and Hispanic individuals are frequently exposed to environmental risk elements (e.g., point-of-sale advertisement, retail display, coupons, and discounts). ${ }^{28}$ This increases the vulnerability of racial/ ethnic and low SES individuals, ${ }^{29}$ a vulnerability that can be summarized as a rapid transition from tobacco initiation, due to addiction, to the development of tobacco-related diseases and undesired outcomes. ${ }^{16,30,31}$

Recent research on Minorities' Diminished Returns (MDRs) $)^{32,33}$ has proposed a new mechanism to explain racial and ethnic health disparities. MDRs refer to the systemically weaker protective effects of SES indicators on health outcomes of racial and ethnic minorities than Whites. According to this theory, at least some of the racial and ethnic disparities in health outcomes are due to the "less than expected" protective health effects of SES indicators. The MDRs model proposes that (a) racial/ethnic inequalities in health are not all due to SES gaps, as some health inequalities persist even at high SES levels, and that (b) in some instances, the racial and ethnic gap in health may widen, rather than narrow, as SES increases. ${ }^{32,33}$ This model highlights the need to study health disparities across all SES levels, and suggests that proposed solutions to health disparities must go beyond merely equalizing SES. They must work to enable high SES ethnic minorities to actualize their potential, and translate their SES into better health. ${ }^{32,33}$

Similar MDRs are shown for tobacco use in Americans. ${ }^{34-36}$ Several studies have documented weaker protective effects of SES indicators on tobacco use in racial and ethnic minorities than Whites. ${ }^{34-36}$ For example, Black people showed a diminished effect of high education levels on cigarette use than Whites. ${ }^{36}$ A similar pattern has been observed for e-cigarette use. ${ }^{37}$ Another study showed a weaker protective effect of employment on Hispanic individuals' smoking status compared to non-Hispanic people. ${ }^{34}$ These patterns are not specific to tobacco and are also observed for alcohol. This suggests that these patterns may be systemic. ${ }^{35,38}$

One of the proposed explanations for more than expected tobacco use in highly educated and high-income Blacks and Hispanics (i.e., MDRs) is flavoring and other marketing strategies of tobacco products. ${ }^{34-36}$ This hypothesis has never been tested before. The hypothesis is based on the observation that Black and Hispanic people may be more likely to use flavored tobacco products. ${ }^{24,39,40}$ Flavored tobacco imposes a higher level of risk to the individual ${ }^{26,28,41-43}$ and, thus, might be a mechanism for some of the racial and ethnic disparities in the tobacco burden. ${ }^{28,42,44,45}$ It has been shown that the use of flavored tobacco products increases addiction, and reduces individuals' ability to quit smoking. . $^{2,42,44,45}$ However, we are not aware of any studies that have tested the relevance of MDRs for SES indicators' effects on smoking initiation using flavored cigarettes. ${ }^{34-36}$

This study tested racial and ethnic variations in the effects of two SES indicators-educational attainment and poverty status-on initiating smoking using flavored cigarettes in a nationally representative sample of American adults. We explored the patterns for any flavored cigarette, and specifically for menthol/mint and candy/fruit flavors (three distinct outcomes). We hypothesized that there would be an inverse association between high SES and smoking initiation using a flavored cigarette. We also expected to observe significant effects of race and ethnicity on smoking initiation using a flavored cigarette. Finally, in line with the MDRs, we expected weaker educational attainment and living out of poverty effects on initiating smoking using a flavored cigarette for Black and Hispanic than for non-Hispanic White Americans. In other words, we expected higher SES Black and Hispanic people to report disproportionately higher odds of initiating smoking using flavored cigarettes, a pattern that would not be observed for non-Hispanic Whites. Such findings would suggest the relevance of initiating smoking using a flavored cigarette as a possible explanation for the MDRs of SES on tobacco use (i.e., high prevalence of tobacco use in high SES non-Whites). ${ }^{34-36}$

\section{Methods \\ PATH Design}

This study was a secondary analysis of existing data. Data came from the Population Assessment of Tobacco and Health (PATH) study. The PATH study is funded by the NIH and FDA to collect updated information on epidemiology and transitions in tobacco use in the US. PATH has approximately 32,000 adults (age 18 years or older). For our study, we used the wave 1 PATH data that was collected in 2013.

\section{PATH Sampling}

The PATH sample was (1) civilian, (2) non-institutionalized, (3) US population, and (4) 18 years of age or older. The PATH study used a four-stage sampling process that included clustering and stratification to recruit an area probability sample of American adults. As a result of this sampling, there is a need to adjust for the sampling weights.

\section{Analytical Sample}

The current analysis only included adults with valid data on our study variables (listed below). Our final analytical sample consisted of 22,144 adults who were ever-smokers.

\section{Study Variables}

The study variables were demographic characteristics (age, gender, and region), race/ethnicity, SES indicators (poverty status and educational attainment), and initiation of smoking using a flavored cigarette. These varaibles were all measured at the individual level. 


\section{Confounders}

Confounders were age, gender, and region. Age was continuous, with a range between 1.0 and 7.0: 1 for 18-24 years old, 2 for 25-34 years old, 3 for 35-44 years old, 4 for 4554 years old, 5 for 55-64 years old, 6 for 65-74 years old, and 7 for $75+$ years old. Gender was a 0/1 dichotomous variable, and was coded with male as the reference group.

\section{Independent Variables}

Educational attainment was a continuous variable ranging from 1 to 6: 1 for less than high school, 2 for GED, 3 for high school graduate, 4 for some college (no degree) or associate's degree, 5 for bachelor's degree, and 6 for advanced degree. Poverty status was a $0 / 1$ dichotomous variable: 0 for living below the $100 \%$ federal poverty line, and 1 for living above the $100 \%$ federal poverty line.

\section{Dependent Variable}

Our outcomes were initiating smoking using flavored cigarettes. These outcomes were measured by asking participants these two items: 1) "Was your first cigarette smoked flavored to taste like menthol or mint?" and 2) "Was your first cigarette smoked flavored to taste like clove, spice, candy, fruit, chocolate, alcohol, or other sweets?" We operationalized these outcomes as binary outcomes: $1=$ initiating smoking using a flavored cigarette, $0=$ initiating smoking using a non-flavored cigarette. Outcomes were 1) menthol/mint, 2) candy/fruit, and 3) any (either).

\section{Moderators}

Race and ethnicity were self-identified and operationalized as binary (0/1) variables: race (Black vs. White) and ethnicity (Hispanic vs. non-Hispanic).

\section{Statistical Analysis}

We analyzed the data using SPSS 23.0 (IBM Corporation, Armonk, NY, US). To adjust for sampling weights, we applied Taylor series linearization. This enabled us to re-estimate the variance of all study variables. By applying weight, the results became generalizable to the US general population. For multivariable analysis, we applied binary logistic regression. We ran two logistic regression models without (Model 1) and with (Model 2) two by four interaction terms between race, ethnicity, educational attainment, and poverty status.

\section{Results}

\section{Descriptive Statistics}

This study included 22,144 American adults who were eversmokers. They were either non-Hispanic (85.1\%), Hispanic (14.9\%), White (84.7\%), or Black (15.3\%).

Table 1 describes demographic, SES, and tobacco use data of the overall sample (Table 1). Participating adults were almost $47 \%$ women and 53\% men. Although most smokers' $(60.7 \%)$ first cigarette was non-flavored, most of the flavored cigarettes were mint/menthol (39.3\% of total), which was considerably higher than people who had started their first smoke with a candy/fruit-flavored product ( $4.5 \%$ only).
Table 1. Descriptive Data in the Overall Sample

\begin{tabular}{|c|c|c|}
\hline & $\mathbf{n}$ & $\%$ \\
\hline \multicolumn{3}{|l|}{ Race } \\
\hline White & 18760 & 84.7 \\
\hline Black & 3384 & 15.3 \\
\hline \multicolumn{3}{|l|}{ Ethnicity } \\
\hline Non-Hispanic & 18845 & 85.1 \\
\hline Hispanic & 3299 & 14.9 \\
\hline \multicolumn{3}{|l|}{ Poverty Status } \\
\hline Living in poverty & 6652 & 32.9 \\
\hline Living out of poverty & 13579 & 67.1 \\
\hline \multicolumn{3}{|l|}{ Gender } \\
\hline Women & 10501 & 47.4 \\
\hline Men & 11643 & 52.6 \\
\hline \multicolumn{3}{|c|}{$\begin{array}{l}\text { Initiating smoking using a flavored cigarette- } \\
\text { Mint/Menthol }\end{array}$} \\
\hline No & 14068 & 63.5 \\
\hline Yes & 8074 & 36.5 \\
\hline \multicolumn{3}{|c|}{$\begin{array}{l}\text { Initiating smoking using a flavored cigarette- } \\
\text { Candy/Fruit }\end{array}$} \\
\hline No & 13436 & 95.5 \\
\hline Yes & 634 & 4.5 \\
\hline \multicolumn{3}{|c|}{$\begin{array}{l}\text { Initiating smoking using a flavored cigarette- } \\
\text { Any }\end{array}$} \\
\hline No & 13436 & 60.7 \\
\hline \multirow[t]{2}{*}{ Yes } & 8708 & 39.3 \\
\hline & Mean & SD \\
\hline Age (1-7) & 3.11 & 1.71 \\
\hline Education (1-6) & 3.49 & 1.37 \\
\hline
\end{tabular}

\section{Multivariable Models}

Table 2 summarizes the output of two logistic regression models with race, ethnicity, educational attainment, and poverty status as the independent variables; and smoking initiation using a flavored cigarette as the dependent variable. Three models were performed for any, menthol/mint, and candy/fruit flavors. All models were estimated in the overall sample and were statistically significant. Model 1 only allowed the main effects of poverty status, race, ethnicity, educational attainment, and covariates. Model 2 also added four interaction terms: race $\mathrm{x}$ educational attainment, ethnicity $\mathrm{x}$ educational attainment, race $\mathrm{x}$ poverty status, and ethnicity $\mathrm{x}$ poverty status.

Based on Model 1, race and ethnicity were associated with initiating smoking using any flavored cigarettes, with Black (odds ratio $[\mathrm{OR}]=3.77,95 \% \mathrm{CI}=3.47-4.11$ ) and Hispanic $(\mathrm{OR}=1.48,95 \% \mathrm{CI}=1.36-1.61)$ people being more likely to report such behavior than non-Hispanic Whites. However, the type of flavor was menthol/mint for Black $(\mathrm{OR}=3.86$, $95 \% \mathrm{CI}=3.55-4.20)$ and candy/fruit for Hispanic ( $\mathrm{OR}=1.79$, $95 \% \mathrm{CI}=1.44-2.21)$ people. Overall, individuals with higher educational attainment had lower odds of initiating smoking using a menthol $/ \mathrm{mint}(\mathrm{OR}=0.94,95 \% \mathrm{CI}=0.92-0.96)$ flavored 
Table 2. Summary of Logistic Regression Models on Initiating Smoking Using a Flavored Cigarette in the Pooled Sample

\begin{tabular}{|c|c|c|c|c|c|c|}
\hline & OR & $95 \% \mathrm{Cl}$ & $\boldsymbol{P}$ & OR & $95 \% \mathrm{Cl}$ & $\boldsymbol{P}$ \\
\hline \multicolumn{7}{|l|}{ Any Flavored } \\
\hline Race (Black) & 3.77 & $3.47-4.11$ & $<0.001$ & 5.16 & $4.12-6.46$ & $<0.001$ \\
\hline Ethnicity (Hispanic) & 1.48 & $1.36-1.61$ & $<0.001$ & 1.25 & $1.02-1.54$ & 0.032 \\
\hline Gender (male) & 0.60 & $0.57-$ & $<0.001$ & 0.60 & $0.57-0.64$ & $<0.001$ \\
\hline Age (1-7) & 0.83 & $0.82-0.85$ & $<0.001$ & 0.83 & $0.82-0.85$ & $<0.001$ \\
\hline Education $(y)$ & 0.98 & $0.95-1.00$ & 0.041 & 0.99 & $0.96-1.01$ & 0.316 \\
\hline Living out of poverty & 0.96 & $0.89-1.03$ & 0.216 & 0.92 & $0.85-1.00$ & 0.065 \\
\hline Education $(y) *$ race $($ Black $)$ & & & & 0.88 & $0.82-0.94$ & $<0.001$ \\
\hline Education $(y) *$ ethnicity (Hispanic) & & & & 1.05 & $0.99-1.12$ & 0.111 \\
\hline Living out of poverty * race (Black) & & & & 1.19 & $1.00-1.43$ & 0.050 \\
\hline Living out of poverty * ethnicity (Hispanic) & & & & 1.02 & $0.86-1.22$ & 0.785 \\
\hline \multicolumn{7}{|l|}{ Menthol/Mint Flavored } \\
\hline Race (Black) & 3.86 & $3.55-4.20$ & $<0.001$ & 5.04 & $4.03-6.30$ & $<0.001$ \\
\hline Ethnicity (Hispanic) & 1.41 & $1.30-1.53$ & $<0.001$ & 1.09 & $0.89-1.34$ & 0.404 \\
\hline Gender (Male) & 0.59 & $0.55-0.62$ & $<0.001$ & 0.59 & $0.55-0.62$ & $<0.001$ \\
\hline Age $(1-7)$ & 0.86 & $0.85-0.88$ & $<0.001$ & 0.86 & $0.85-0.88$ & $<0.001$ \\
\hline Education (y) & 0.94 & $0.92-0.96$ & $<0.001$ & 0.94 & $0.91-0.97$ & $<0.001$ \\
\hline Living out of poverty & 0.95 & $0.89-1.02$ & 0.157 & 0.92 & $0.84-1.00$ & 0.050 \\
\hline Education $(y) *$ race $($ Black $)$ & & & & 0.90 & $0.84-0.96$ & 0.002 \\
\hline Education $(y) *$ ethnicity (Hispanic) & & & & 1.08 & $1.01-1.14$ & 0.023 \\
\hline Living out of poverty * race (Black) & & & & 1.14 & $0.96-1.36$ & 0.145 \\
\hline Living out of poverty * ethnicity (Hispanic) & & & & 1.06 & $0.89-1.27$ & 0.519 \\
\hline \multicolumn{7}{|l|}{ Fruit and Candy Flavored } \\
\hline Race (Black) & 1.35 & $1.03-1.78$ & 0.031 & 1.41 & $0.59-3.35$ & 0.442 \\
\hline Ethnicity (Hispanic) & 1.79 & $1.44-2.21$ & $<0.001$ & 3.98 & $2.19-7.25$ & $<0.001$ \\
\hline Gender (male) & 0.91 & $0.77-1.08$ & 0.274 & 0.90 & $0.76-1.07$ & 0.222 \\
\hline Age $(1-7)$ & 0.66 & $0.62-0.70$ & $<0.001$ & 0.66 & $0.62-0.70$ & $<0.001$ \\
\hline Education (y) & 1.35 & $1.26-1.45$ & $<0.001$ & 1.43 & $1.31-1.56$ & $<0.001$ \\
\hline Living out of poverty & 1.04 & $0.85-1.27$ & 0.692 & 1.02 & $0.79-1.31$ & 0.904 \\
\hline Education $(y) *$ race $($ Black $)$ & & & & 0.91 & $0.72-1.15$ & 0.431 \\
\hline Education $(y) *$ ethnicity (Hispanic) & & & & 0.82 & $0.69-0.97$ & 0.020 \\
\hline Living out of poverty * race (Black) & & & & 1.76 & $0.96-3.23$ & 0.067 \\
\hline Living out of poverty * ethnicity (Hispanic) & & & & 0.85 & $0.54-1.34$ & 0.482 \\
\hline Constant & 0.04 & & $<0.001$ & 0.04 & & $<0.001$ \\
\hline
\end{tabular}

Cl: confidence interval; SE: standard error; OR: odds ratio.

cigarette, but higher odds of using a candy/fruit $(\mathrm{OR}=1.35$, 95\% CI $=1.26-1.45$ ) flavored cigarette. Living out of poverty did not have any association with smoking initiation using either flavored cigarettes.

Based on Model 2, education had a larger protective effect for Blacks against initiating their smoking using any $(\mathrm{OR}=0.88,95 \% \mathrm{CI}=0.82-0.94)$ or menthol $/ \mathrm{mint}(\mathrm{OR}=0.90$, 95\% CI $=0.84-0.96)$ flavored cigarettes. However, race did not alter educational attainment on initiating smoking using candy/fruit-flavored cigarettes. Hispanic ethnicity showed a significant interaction with education on initiating smoking using menthol $/$ mint cigarettes $(\mathrm{OR}=1.08,95 \% \mathrm{CI}=1.01$ -
1.14), suggesting that education may lose some of its protective effects on reducing the odds of initiating smoking using menthol/mint-flavored cigarettes for Hispanics than for non-Hispanics. Hispanic ethnicity also showed a significant interaction with education on initiating smoking using candy/ fruit-flavored cigarettes $(\mathrm{OR}=0.82,95 \% \mathrm{CI}=0.69-0.97)$, suggesting that education may better protect Hispanics than non-Hispanics against initiating smoking using candy/fruitflavored cigarettes. Living out of poverty showed a significant interaction with race on odds of initiating smoking using any flavored cigarettes $(\mathrm{OR}=1.19,95 \% \mathrm{CI}=1.00-1.43)$ as well, suggesting that living out of poverty has a larger protective 
effect for White than for Black people.

\section{Discussion}

The current study produced several findings. First, racial and ethnic minority adults were more likely to report that they had initiated smoking using a flavored cigarette. However, Blacks and Hispanics were at risk of initiating smoking with different flavors of cigarettes. Blacks had a higher tendency to initiate with menthol/mint-flavored cigarettes, whereas Hispanics more frequently initiated with candy/fruit-flavored cigarettes. Second, overall, educational attainment reduces the odds of initiating smoking using flavored cigarettes. However, living out of poverty was not directly associated with initiating smoking using a flavored cigarette after controlling for education. Third, we found interactions between race and ethnicity from one side, and education and poverty status from the other side, on our outcomes. However, these interactions were complex and were specific to race, ethnicity, SES indicator, and type of flavor.

In our study, Black $(\mathrm{OR}=3.86)$ and Hispanic $(\mathrm{OR}=1.79)$ people had higher odds of initiating smoking using menthol/ mint and candy/fruit-flavored cigarettes, respectively. Although tobacco researchers have noted cigarette flavoring as a marketing strategy that places racial and ethnic minorities and low SES people at risk, ${ }^{34-36}$ less is known about the nuances on how each race and ethnic group initiate smoking using flavored cigarettes, and how people from various contexts differ in this regard. Our findings are in line with the general observation that Black and Hispanic people are more likely to use flavored tobacco products. ${ }^{24,39,40}$

Building on our previous work on MDRs, we expected a higher risk of tobacco use initiation with flavored products in high SES Black and Hispanic people. We found some support for our hypothesis. Our study confirmed that (a) education showed a weaker $(\mathrm{OR}=1.08)$ protective effect on reducing the odds of initiating smoking using menthol/mint-flavored cigarettes for Hispanics, and that $(b)$ living out of poverty had a weaker protective effect for Blacks than Whites on the odds of initiating smoking using any flavored cigarettes $(\mathrm{OR}=1.19)$.

At the same time, some findings did not confirm our hypothesis. Contrary to our expectations, our study found that (a) education had a larger protective effect for Blacks against smoking initiation using any $(\mathrm{OR}=0.88)$ or menthol $/ \mathrm{mint}$ $(\mathrm{OR}=0.90)$ flavored cigarettes, and that $(b)$ education better protected Hispanics than non-Hispanics against smoking initiation using candy/fruit-flavored cigarettes $(\mathrm{OR}=0.82)$. More research is needed on the circumstances in which MDRs hold and the contexts, situations, and populations in which MDRs do not hold. In this view, MDRs proposed a framework that may not fully apply to all SES indicators, tobacco products, age groups, ethnic groups, and locations.

Our results demonstrate the high level of complexity in the interplays between race, ethnicity, SES indicator, and flavor type. For example, individuals with higher educational attainment had lower odds of smoking initiation using menthol/mint $(\mathrm{OR}=0.94)$ flavored cigarettes, but higher odds of smoking initiation using candy/fruit $(\mathrm{OR}=1.35)$ flavored cigarettes. Simultaneously, living out of poverty did not have any residual effect on initiating smoking using either flavored cigarettes after controlling for education.

Previous studies have documented an increased risk of substance use in high SES Black and Hispanic individuals compared to high SES White people. ${ }^{35,36,38,46}$ These patterns are not limited to tobacco and are observed for a wide range of health, mental, physical, and behavioral outcomes as well. ${ }^{32,33}$

More research is needed on the role of predatory tobacco marketing practices in increasing the risk of initiating smoking using a flavored cigarette in high-income Blacks. Predatory marketing practices have been mentioned as a mechanism behind the racial, ethnic, and SES health disparities in tobacco use. It can be hypothesized that such marketing practices may potentially generate MDRs. That is, predatory marketing and advertising have the potential to disproportionately impact flavored tobacco use in high SES Blacks. If this hypothesis proves true, we would need to introduce more restrictive marketing policies that reduce point-of-sale advertisements and flavoring. Not only would these policies reduce the overall smoking rate, they would also greatly reduce smoking in high SES Black people. Restrictions and bans on predatory marketing may also be needed to eliminate tobacco disparities by race and ethnicity. That said, more research is needed to explore this hypothesis. ${ }^{47}$

\section{Implications}

For the FDA, NIH, and CDC, eliminating racial, ethnic, and economic health disparities is a strategic goal. A research priority of the FDA is to "[understand] why people become susceptible to using tobacco products." Knowing why subgroups become more prone or vulnerable to tobacco may have some policy and public health implications, and help the FDA, NIH, and CDC act on their priorities. We have argued that public health policies aimed at reducing tobaccorelated disparities need to go beyond reducing SES gaps to addressing MDRs of SES in Blacks and Hispanics. Policies that more tightly regulate the advertisement of flavored tobacco products may be needed. US policymakers should not overemphasize individual choices. Instead, they should seek to tighten regulations that can limit the effects of structural risk factors. ${ }^{48}$ The good news is that, in general, the American public do not perceive restrictive tobacco policies as a threat to their individual freedom and agency. ${ }^{48}$

There is a need for regulatory policies at both the national and local levels to reduce the racial, ethnic, and SES disparities in tobacco use. We still do not know if these policy changes would reduce or increase SES's existing MDRs on tobacco use. There is a need to study the role of discounts, coupons, and flavoring in shaping MDRs of SES on tobacco use for high SES Blacks and Hispanics. ${ }^{35,36}$ The exact type of tobacco regulations and policies that can undo the MDRs of SES on tobacco use for high SES Blacks and Hispanics are still unknown as well. $35,36,38,46$

Since flavored tobacco imposes a higher risk to the individual, ${ }^{26,28,41-43}$ there is a need to ban marketing strategies that increase the risk of Black, Hispanic, and other 
Research Highlights

\section{What Is Already Known?}

Use of flavored tobacco products may vary across social groups. Race, ethnicity, and SES are among social determinants of use of flavored tobacco products.

\section{What Does This Study Add?}

Social groups by race and ethnicity differ in the effects of their SES on their use of flavored tobacco products at first cigarette smoking. The effects of race, ethnicity, and SES on the use of flavored tobacco products at first cigarette smoking are not additive but multiplicative.

marginalized and vulnerable groups. Furthermore, since using flavored tobacco products may increase addiction and reduce individuals' ability to quit smoking, ${ }^{28,42,44,45}$ there is a need to boost ethnic minorities' access to tobacco cessation treatments (given their higher needs because of the flavored nature of their initiation). It is unknown if more restrictive policies would reduce the racial and ethnic disparities in the tobacco burden, ${ }^{28,42,44,45}$ and whether they would have an effect on disparities that are shaped by MDRs (i.e., reduced effects of SES on high SES racial and ethnic minorities).

\section{Limitations}

This study had some methodological and conceptual limitations. Cross-sectional studies do not show causal effects but associations instead. The PATH sample size was imbalanced with a higher $\mathrm{n}$ in non-Hispanic Whites than in Hispanics and Blacks. Another limitation was a lack of information on income, employment, marital status, wealth, and area-level SES indicators. Although these limitations exist, the results of this study still contribute to the existing literature.

\section{Conclusion}

In the US, race and ethnicity modify the association between SES indicators (such as education and income) on first tobacco flavor. The association between SES and first cigarette flavor is complicated and depends on the intersections of race, ethnicity, and SES. More research is needed on the complex interplays between these social constructs in shaping racial, ethnic, and economic disparities in tobacco use. Such research may help promote population health.

\section{Conflicts of Interest Disclosures}

The author declares no conflicts of interest.

\section{Ethical Approval}

This analysis was not considered human research because it used fully de-identified publicly available data. Thus, Charles R Drew University excepted the current study from a full IRB review. Participants of PATH provided written consent, and the Westat Institutional Review Board (IRB) approved the original (i.e., PATH) study protocol.

\section{Funding/Support}

Shervin Assari is supported by the grants with the numbers
CA201415 02, 5S21MD000103, DA035811-05, U54MD007598, U54MD008149, D084526-03, and U54CA229974 by the National Institutes of Health (NIH).

\section{References}

1. Jette AM, Feldman HA, Tennstedt SL. Tobacco use: a modifiable risk factor for dental disease among the elderly. Am J Public Health. 1993;83(9):1271-1276. doi:10.2105/ajph.83.9.1271.

2. Makomaski Illing EM, Kaiserman MJ. Mortality attributable to tobacco use in Canada and its regions, 1998. Can J Public Health. 2004;95(1):38-44. doi:10.1007/bf03403632.

3. Brugere J, Guenel P, Leclerc A, Rodriguez J. Differential effects of tobacco and alcohol in cancer of the larynx, pharynx, and mouth. Cancer. 1986;57(2):391-395. doi:10.1002/10970142(19860115)57:2<391::aid-cncr2820570235>3.0.co;2-q.

4. Johnson N. Tobacco use and oral cancer: a global perspective. J Dent Educ. 2001;65(4):328-339. doi:10.1002/j.00220337.2001.65.4.tb03403.x.

5. Vellappally S, Fiala Z, Smejkalová J, Jacob V, Shriharsha P. Influence of tobacco use in dental caries development. Cent Eur J Public Health. 2007;15(3):116-121. doi:10.21101/cejph.a3431.

6. Petersen PE. Tobacco and oral health--the role of the world health organization. Oral Health Prev Dent. 2003;1(4):309-315.

7. Pindborg JJ. Tobacco and gingivitis: statistical examination of the significance of tobacco in the development of ulceromembranous gingivitis and in the formation of calculus. J Dent Res. 1947;26(3):261-264. doi:10.1177/002203454702600 30901 .

8. Sham AS, Cheung LK, Jin LJ, Corbet EF. The effects of tobacco use on oral health. Hong Kong Med J. 2003;9(4):271-277.

9. McCarthy M. Smoking remains leading cause of premature death in US. BMJ. 2014;348:g396. doi:10.1136/bmj.g396.

10. Samet JM. Tobacco smoking: the leading cause of preventable disease worldwide. Thorac Surg Clin. 2013;23(2):103-112. doi:10.1016/j.thorsurg.2013.01.009.

11. Novick LF. Smoking is the leading preventable cause of death and disability in the United States. J Public Health Manag Pract. 2000;6(3):vi. doi:10.1097/00124784-200006030-00001.

12. Centers for Disease Control and Prevention (CDC). Smoking \& Tobacco Use. Fast Facts. CDC; 2019.

13. Centers for Disease Control and Prevention (CDC). Economic Trends in Tobacco. https://www.cdc.gov/tobacco/data statistics/fact_sheets/economics/index.htm.

14. Ellickson PL, Orlando M, Tucker JS, Klein DJ. From adolescence to young adulthood: racial/ethnic disparities in smoking. Am J Public Health. 2004;94(2):293-299. doi:10.2105/ajph.94.2.293.

15. Centers for Disease Control and Prevention (CDC). Racial disparities in smoking-attributable mortality and years of potential life lost --- Missouri, 2003-2007. MMWR Morb Mortal Wkly Rep. 2010;59(46):1518-1522.

16. Trinidad DR, Pérez-Stable EJ, White MM, Emery SL, Messer K. A nationwide analysis of US racial/ethnic disparities in smoking behaviors, smoking cessation, and cessation-related factors. Am J Public Health. 2011;101(4):699-706. doi:10.2105/ ajph.2010.191668.

17. Soulakova JN, Huang H, Crockett LJ. Racial/ethnic disparities in consistent reporting of smoking-related behaviors. J Addict Behav Ther Rehabil. 2015;4(4). doi:10.4172/23249005.1000147.

18. Blumenthal DS. Racial and ethnic disparities in smoking prevalence in Israel and the United States: progress to date and prospects for the future. Isr J Health Policy Res. 2017;6(1):51. doi:10.1186/s13584-017-0177-9.

19. Drope J, Liber AC, Cahn Z, et al. Who's still smoking? disparities in adult cigarette smoking prevalence in the United States. CA 
Cancer J Clin. 2018;68(2):106-115. doi:10.3322/caac.21444.

20. Laveist TA, Thorpe RJ Jr, Mance GA, Jackson J. Overcoming confounding of race with socio-economic status and segregation to explore race disparities in smoking. Addiction. 2007;102 Suppl 2:65-70. doi:10.1111/j.1360-0443.2007.01956.x.

21. Reid JL, Hammond D, Driezen P. Socio-economic status and smoking in Canada, 1999-2006: has there been any progress on disparities in tobacco use? Can J Public Health. 2010;101(1):7378. doi:10.1007/bf03405567.

22. Zhang X, Martinez-Donate AP, Jones NR. Educational disparities in home smoking bans among households with underage children in the United States: can tobacco control policies help to narrow the gap? Nicotine Tob Res. 2013;15(12):1978-1987. doi:10.1093/ntr/ntt090.

23. Reimer RA, Gerrard M, Gibbons FX. Racial disparities in smoking knowledge among current smokers: data from the health information national trends surveys. Psychol Health. 2010;25(8):943-959. doi:10.1080/08870440902935913.

24. Rock VJ, Davis SP, Thorne SL, Asman KJ, Caraballo RS. Menthol cigarette use among racial and ethnic groups in the United States, 2004-2008. Nicotine Tob Res. 2010;12 Suppl 2:S117-124. doi:10.1093/ntr/ntq204.

25. Terry-McElrath YM, Wakefield MA, Emery S, et al. State anti-tobacco advertising and smoking outcomes by gender and race/ethnicity. Ethn Health. 2007;12(4):339-362. doi:10.1080/13557850701300723.

26. Keeler C, Max W, Yerger V, Yao T, Ong MK, Sung HY. The association of menthol cigarette use with quit attempts, successful cessation, and intention to quit across racial/ethnic groups in the United States. Nicotine Tob Res. 2017;19(12):14501464. doi:10.1093/ntr/ntw215.

27. Giovenco DP, Spillane TE, Merizier JM. Neighborhood differences in alternative tobacco product availability and advertising in New York City: implications for health disparities. Nicotine Tob Res. 2019;21(7):896-902. doi:10.1093/ntr/nty244.

28. Anderson SJ. Marketing of menthol cigarettes and consumer perceptions: a review of tobacco industry documents. Tob Control. 2011;20 Suppl 2:ii20-28. doi:10.1136/tc.2010.041939.

29. Greaves L, Hemsing N. Women and tobacco control policies: social-structural and psychosocial contributions to vulnerability to tobacco use and exposure. Drug Alcohol Depend. 2009;104 Suppl 1:S121-130. doi:10.1016/j.drugalcdep.2009.05.001.

30. Cokkinides VE, Halpern MT, Barbeau EM, Ward E, Thun MJ. Racial and ethnic disparities in smoking-cessation interventions: analysis of the 2005 National Health Interview Survey. Am J Prev Med. 2008;34(5):404-412. doi:10.1016/j. amepre.2008.02.003.

31. Tran ST, Rosenberg KD, Carlson NE. Racial/ethnic disparities in the receipt of smoking cessation interventions during prenatal care. Matern Child Health J. 2010;14(6):901-909. doi:10.1007/ s10995-009-0522-x.

32. Assari S. Health disparities due to diminished return among Black Americans: public policy solutions. Soc Issues Policy Rev. 2018;12(1):112-145. doi:10.1111/sipr.12042.

33. Assari S. Unequal gain of equal resources across racial groups. Int J Health Policy Manag. 2018;7(1):1-9. doi:10.15171/ ijhpm.2017.90.

34. Assari S, Mistry R. Diminished return of employment on ever smoking among Hispanic Whites in Los Angeles. Health
Equity. 2019;3(1):138-144. doi:10.1089/heq.2018.0070

35. Assari S, Farokhnia M, Mistry R. Education attainment and alcohol binge drinking: diminished returns of Hispanics in Los Angeles. Behav Sci (Basel). 2019;9(1):9. doi:10.3390/bs9010009.

36. Nguyen-Grozavu FT, Pierce JP, Sakuma KK, Leas EC, McMenamin SB, Kealey S, et al. Widening disparities in cigarette smoking by race/ethnicity across education level in the United States. Prev Med. 2020;139:106220. doi:10.1016/j. ypmed.2020.106220.

37. Assari S, Mistry R, Bazargan M. Race, educational attainment, and E-cigarette use. J Med Res Innov. 2020;4(1). doi:10.32892/ jmri.185.

38. Assari S, Moghani Lankarani M. Education and alcohol consumption among older Americans; Black-White differences. Front Public Health. 2016;4:67. doi:10.3389/fpubh.2016.00067.

39. Jones MR, Apelberg BJ, Tellez-Plaza M, Samet JM, NavasAcien A. Menthol cigarettes, race/ethnicity, and biomarkers of tobacco use in U.S. adults: the 1999-2010 National Health and Nutrition Examination Survey (NHANES). Cancer Epidemiol Biomarkers Prev. 2013;22(2):224-232. doi:10.1158/1055-9965. epi-12-0912.

40. Mustonen TK, Spencer SM, Hoskinson RA, Sachs DP, Garvey AJ. The influence of gender, race, and menthol content on tobacco exposure measures. Nicotine Tob Res. 2005;7(4):581590. doi:10.1080/14622200500185199.

41. Schneller LM, Bansal-Travers M, Goniewicz ML, McIntosh S, Ossip D, O'Connor RJ. Use of flavored electronic cigarette refill liquids among adults and youth in the US-results from Wave 2 of the Population Assessment of Tobacco and Health Study (2014-2015). PLoS One. 2018;13(8):e0202744. doi:10.1371/ journal.pone.0202744.

42. Cubbin C, Soobader MJ, LeClere FB. The intersection of gender and race/ethnicity in smoking behaviors among menthol and non-menthol smokers in the United States. Addiction. 2010;105 Suppl 1:32-38. doi:10.1111/j.1360-0443.2010.03191.x.

43. Gundersen DA, Delnevo CD, Wackowski O. Exploring the relationship between race/ethnicity, menthol smoking, and cessation, in a nationally representative sample of adults. Prev Med. 2009;49(6):553-557. doi:10.1016/j.ypmed.2009.10.003.

44. Fernander A, Rayens MK, Hahn E, Zhang M, Adkins SM. Menthol smoking, smoke-free policies and cessation services. Addiction. 2010;105 Suppl 1:105-114. doi:10.1111/j.13600443.2010.03189.x.

45. Trinidad DR, Pérez-Stable EJ, Messer K, White MM, Pierce JP. Menthol cigarettes and smoking cessation among racial/ethnic groups in the United States. Addiction. 2010;105 Suppl 1:84-94. doi:10.1111/j.1360-0443.2010.03187.x.

46. Assari S, Mistry R. Educational attainment and smoking status in a national sample of American adults; evidence for the Blacks' diminished return. Int J Environ Res Public Health. 2018;15(4):763. doi:10.3390/ijerph15040763.

47. Soneji S, Knutzen KE, Tan ASL, et al. Online tobacco marketing among US adolescent sexual, gender, racial, and ethnic minorities. Addict Behav. 2019;95:189-196. doi:10.1016/j. addbeh.2019.03.015.

48. Feliu A, Filippidis FT, Joossens L, et al. Impact of tobacco control policies on smoking prevalence and quit ratios in 27 European Union countries from 2006 to 2014. Tob Control. 2019;28(1):101-109. doi:10.1136/tobaccocontrol-2017-054119. 